\title{
Patients with low back pain in Malawi: Their attitudes and beliefs on their low back pain
}

\author{
Tarimo Nesto ${ }^{1}$, Ina Diener ${ }^{2}$ \\ ${ }^{1}$ Rehabilitation Technicians School, Malawi Against Physical Disabilities P.O. Box 256, Blantyre, Malawi \\ ${ }^{2}$ University of the Western Cape, Private Bag X17, Cape Town, South Africa \\ Email address: \\ tarimonesto@gmail.com (N.S. Tarimo)

\section{To cite this article:} \\ Tarimo Nesto, Ina Diener. Patients with Low Back Pain in Malawi: Their Attitudes and Beliefs on Their Low Back Pain. Clinical \\ Medicine Research. Vol. 3, No. 4, 2014, pp. 112-118. doi: 10.11648/j.cmr.20140304.16
}

\begin{abstract}
Low back pain (LBP) is a musculoskeletal disorder, affecting humans from adolescent to adult age. It is a health and socio-economic problem worldwide. The cause and contributing factors to LBP are multifactorial resulting in different approaches for its management. The attitudes and beliefs of patient with LBP, play an important role in the whole process of pain management. Negative attitudes and beliefs may lead to fear -avoidance behaviour, resulting into pain chronicity and disability. Thus, this study aimed to identify the attitudes and beliefs among patients with LBP, attending physiotherapy treatment in Malawi. Queen Elizabeth and Kamuzu Central hospitals were selected as study settings. A quantitative cross-sectional survey was done, using a self-administered questionnaire, employing a convenience sampling method. Twelve statements about attitudes and beliefs on LBP were adopted from the Back Beliefs Questionnaire (BBQ) and from the Survey of Pain Attitudes (SOPA). The SPSS (version 19.0) was used for data capturing and analysis. Descriptive and inferential statistics were used to summarize data. The Chi-square test was used to determine any association between variables and the Alpha level of significance was set at 0.05. All ethical issues were sought and adhered to throughout the study period. The results showed that out of 205 participants, with mean age of 47.74 years, $(\mathrm{SD}=13.29)$, female constituted $53.2 \%$ of the sample. More than half $(67 \%)$ of all participants portrayed negative attitudes and beliefs about their LBP. We concluded that, majority of patients with LBP in Malawi hold negative attitudes and beliefs about their pain. Therefore, patient health education is needed to change these attitudes and beliefs if recovery and treatment goal are to be achieved.
\end{abstract}

Keywords: Low Back Pain, Attitudes, Beliefs

\section{Introduction}

Low back pain (LBP) has both health and socioeconomic burden in one's life. It affects everybody regardless of age and gender [1, 2]. Its prevalence is on rise, both in developing and developed countries. About 8 out of 10 people will experience a disabling episode of LBP at one point during their life time [3]. In Africa alone, the life time prevalence is $28 \%$ to $74 \%$ [4] while globally is between $50 \%$ to $84 \%$ [5]. Although the prevalence is high, LBP etiology remains controversial, because its cause and contributing factors are diverse and multifactorial [6]. This has led the health personnel involved in the management of LBP to use different treatment approaches during management of LBP. These approaches include exercises, self-care and provision of patient education booklet regarding their pain [7].
During caring patients with LBP, Ng'urah and Frantz [8] emphasize the need to provide patients with sufficient information about the cause of their pain and how it will be managed. Notably, majority of patients with LBP do not understand the cause of their LBP and the main reason for them to visit health facilities is that they want to be educated, establish the cause of their pain and its management [9].

Henrotin et al. [10] argue that, when LBP patients are not provided with a satisfactory explanation for their pain, they tend to have some pre-occupied ideas, which may lead them to source the information about the cause of their pain elsewhere. This may result in patients ending up getting wrong information from unreliable sources which could lead to maladaptive behaviours, negative attitudes and beliefs on their LBP [10].Therefore identifying patients' attitudes and beliefs on their pain is essential during 
management of LBP, because their attitudes and beliefs have an impact on achieving the treatment goal [11].For instance, Symond et al [12] argue that, patient's positive attitude and beliefs towards their pain, facilitates the achievement of the rehabilitation goal and plays a major role in the recovery process. Furthermore, it influences the patient in returning to functional activity and participation [13].Consequently, May [14]stressed the importance of the therapist to first explore the patient's attitudes and beliefs regarding their back pain, followed by changing this negative attitudes and beliefs by providing the patients with health education about their LBP. The primary aim of this study was therefore, to identify the attitudes and beliefs among patients with LBP who attend physiotherapy treatment in selected hospitals in Malawi.

\section{Materials and Methods}

\subsection{Subjects}

The participants for this study were 205 patients with LBP. They were recruited as they came for treatment to the two selected hospitals (Queen Elizabeth and Kamuzu Central hospitals).These hospitals were selected because their locations were geographically convenient to the researcher, and they are the only central hospitals where the physiotherapy departments are headed by physiotherapists.

\subsection{Inclusion and Exclusion Criteria}

All patients with LBP and low back related pain, who were receiving physiotherapy treatment as outpatients, were included in the study. But those diagnosed with serious spinal pathologies for example, infections like TB spine, tumours, were excluded from the study.

\subsection{Sampling Technique}

A convenience time-constraint sampling method was used to draw participants from the population. Every patient with LBP receiving treatment at the outpatient departments of the selected hospitals within the time scope of data collection, and meeting the inclusion criteria for the study, was recruited.

\subsection{Research Design}

The study was a quantitative cross-sectional survey. This study design was considered appropriate because the data collection had to be carried out in one particular point in time [15]; it is the best design in describing the relationship of a phenomenon at one point in time, and easy to manage within a limited timeframe [15].

\subsection{Instrumentation}

A self-administered questionnaire was used. It contained the social demographic data of the participants and the twelve statements adopted from the BBQ and SOPA questionnaires to capture the attitudes and beliefs of the participants. The pilot study was done to ascertain the reliability of the instrument. Experts in the field of low back pain were involved to ensure the content validity of the instrument. A five Likert scale ranging from 'strongly agree' to 'strongly disagree' on the 12 statements was used to explore the opinion of the participants about their LBP.

\subsection{Procedure}

The ethical clearance was obtained from the University of the Western Cape Research Grants and Study Leave Committee and from the Ethics Research Committee of College of Medicine in Malawi. Permission letters were also obtained from the hospital directors of the two selected hospitals. The participants were furnished with the information about the aim of the study, and upon agreeing to participate; they were requested to sign an informed consent form. To maintain privacy and confidentiality, no names were used and the questionnaires were filled by participants in a quiet and secluded room. The questionnaires were immediately collected by the researcher with assistance of two trained research assistants and were locked in the drawer, accessible only by the researcher.

\subsection{Data Analysis}

Table 1. Socio- demographic characteristics of the study sample $(n=205)$

\begin{tabular}{|c|c|c|}
\hline \multirow{2}{*}{ Variable } & \multicolumn{2}{|c|}{ Frequency } \\
\hline & (n) & $(\%)$ \\
\hline \multicolumn{3}{|l|}{ Gender } \\
\hline Males & 96 & 46.8 \\
\hline Females & 109 & 53.2 \\
\hline \multicolumn{3}{|l|}{ Age group } \\
\hline 15-24years & 8 & 3.9 \\
\hline 25-34years & 27 & 13.2 \\
\hline 35-44years & 44 & 21.5 \\
\hline 45- 54years & 62 & 30.2 \\
\hline 55- 64years & 43 & 21.0 \\
\hline$\geq 65$ years & 21 & 10.2 \\
\hline \multicolumn{3}{|l|}{ Level of education } \\
\hline Never went to school & 66 & 32.0 \\
\hline Primary level & 98 & 47.8 \\
\hline Secondary level & 34 & 16.6 \\
\hline Tertiary level & 7 & 3.4 \\
\hline \multicolumn{3}{|l|}{ Marital status } \\
\hline Single & 48 & 23.4 \\
\hline Married & 104 & 50.7 \\
\hline Divorced & 19 & 9.3 \\
\hline Separated & 3 & 1.5 \\
\hline Widow & 25 & 12.2 \\
\hline Widower & 6 & 2.9 \\
\hline \multicolumn{3}{|l|}{ Residential area } \\
\hline Rural & 47 & 22.9 \\
\hline Urban & 158 & 77.1 \\
\hline
\end{tabular}

Mean age 47.74 years $(\mathrm{SD}=13.29)$.

The SPSS version 19.0 was used for data capturing and analysis. The data was summarized by using descriptive statistics and is expressed in frequencies, percentages, mean and standard deviations. Inferential statistics was also used to determine the association between the variables 
such as gender, age, marital status and education. The ChiSquare tests was used to test for any significant association, and the Alpha level of significance was set at 0.05 .

\section{Results}

A total number of 205 patients with LBP voluntarily consented to participate in the study. The results showed that female were majority in this study $53.2 \%$ (109). The participants ages ranged from 17 to 82 years with a mean age of 47.74 years (Standard deviation $(\mathrm{SD})=13.29$ ). The majority of the participants $50.7 \%$ (104) were married, and most of them with only primary education level. The demographic data of the participants is presented on Table 1.

Participants' attitudes and beliefs regarding their LBP were tested with the series of twelve statements (Obtained from Back Beliefs Questionnaire and Survey of Pain Attitudes questionnaire). Table 2 presents the participants' responses as per statement. Their responses on each statement ranged from "strongly agree" to "strongly disagree". Their responses were further collated into "Agree" "Don't know" and "Disagree" and were further analysed as shown in Table 3.

Table 2. Participants' opinions on their own LBP in general $(n=205)$

\begin{tabular}{|c|c|c|c|c|c|c|}
\hline \multirow{2}{*}{\multicolumn{2}{|c|}{ Statements }} & \multicolumn{5}{|c|}{ Responses (\%) } \\
\hline & & \multirow{2}{*}{$\frac{\mathbf{S A} *}{56.1 \%}$} & \multirow{2}{*}{$\frac{A^{*}}{36.6 \%}$} & \multirow{2}{*}{$\frac{\mathrm{DN} *}{2.4 \%}$} & \multirow{2}{*}{$\begin{array}{l}* \\
3.4 \%\end{array}$} & \multirow{2}{*}{$\begin{array}{l}\text { SD* } \\
1.5 \%\end{array}$} \\
\hline 1. & People with LBP should avoid movement as may cause more injury & & & & & \\
\hline 2. & Pain acceptance facilitates recovery from LBP & $26.3 \%$ & $27.8 \%$ & $17.6 \%$ & $24.9 \%$ & $3.4 \%$ \\
\hline 3. & Only health personnel can cure LBP & $53.2 \%$ & $32.2 \%$ & $4.4 \%$ & $7.3 \%$ & $2.9 \%$ \\
\hline 4. & Self -management on your LBP has no effect on recovery & $14.1 \%$ & $25.9 \%$ & $23.9 \%$ & $30.7 \%$ & $5.4 \%$ \\
\hline 5. & LBP will eventually stop you from working & $30.7 \%$ & $41.0 \%$ & $10.7 \%$ & $14.1 \%$ & $3.4 \%$ \\
\hline 6. & Your LBP will last with you for the rest of your life & $4.4 \%$ & $8.3 \%$ & $40.5 \%$ & $32.7 \%$ & $14.1 \%$ \\
\hline 7. & LBP will never stop you doing what you really want to do & $10.2 \%$ & $31.2 \%$ & $13.7 \%$ & $38.0 \%$ & $6.8 \%$ \\
\hline 8. & $\begin{array}{l}\text { Because of your LBP, abstain your duties and avoid physical } \\
\text { activity }\end{array}$ & $23.4 \%$ & $44.9 \%$ & $6.8 \%$ & $16.1 \%$ & $8.8 \%$ \\
\hline 9. & Having LBP, may mean you will end up with disability & $8.3 \%$ & $18.5 \%$ & $25.9 \%$ & $29.3 \%$ & $18.0 \%$ \\
\hline 10. & $\begin{array}{l}\text { You can control the amount of pain you feel by changing your } \\
\text { thoughts }\end{array}$ & $10.2 \%$ & $21.0 \%$ & $32.2 \%$ & $31.2 \%$ & $5.4 \%$ \\
\hline 11. & To know your pain, the best way is to go to the health care facility & $62.9 \%$ & $30.2 \%$ & $2.9 \%$ & $3.4 \%$ & $0.5 \%$ \\
\hline 12. & LBP gets progressively worse later in life & $30.7 \%$ & $39.0 \%$ & $19.0 \%$ & $10.2 \%$ & $1.0 \%$ \\
\hline
\end{tabular}

*SA=Strongly Agree, ${ }^{*} \mathrm{~A}=$ Agree, ${ }^{*} \mathrm{DN}=$ Do not know, ${ }^{*} \mathrm{D}=$ Disagree, ${ }^{*} \mathrm{SD}=$ Strongly Disagree

Table 3. Summary of responses of participants on attitudes and beliefs about their own LBP ( $n=205)$

\begin{tabular}{|c|c|c|c|c|}
\hline \multirow{2}{*}{\multicolumn{2}{|c|}{ Statements }} & \multicolumn{3}{|c|}{ Responses (\%) } \\
\hline & & \multirow{2}{*}{$\begin{array}{l}\mathbf{A} * \\
92.7 \%\end{array}$} & \multirow{2}{*}{$\frac{\text { DN* }}{2.4 \%}$} & \multirow{2}{*}{$\begin{array}{l}\text { D* } \\
4.9 \%\end{array}$} \\
\hline 1. & People with LBP should avoid movement as may cause more injury & & & \\
\hline 2. & Pain acceptance facilitates recovery from LBP & $54.1 \%$ & $17.6 \%$ & $28.3 \%$ \\
\hline 3. & Only health personnel can cure LBP & $85.4 \%$ & $4.4 \%$ & $10.2 \%$ \\
\hline 4. & Self -management on your LBP has no effect on recovery & $40.0 \%$ & $23.9 \%$ & $36.1 \%$ \\
\hline 5. & LBP will eventually stop you from working & $69.8 \%$ & $19.0 \%$ & $11.2 \%$ \\
\hline 6. & Your LBP will last with you for the rest of your life & $12.7 \%$ & $40.5 \%$ & $46.8 \%$ \\
\hline 7. & LBP will never stop you doing what you really want to do & $31.2 \%$ & $32.2 \%$ & $36.6 \%$ \\
\hline 8. & Because of your LBP, abstain your duties and avoid physical activity & $41.5 \%$ & $13.7 \%$ & $44.8 \%$ \\
\hline 9. & Having LBP, may mean you will end up with disability & $68.3 \%$ & $6.8 \%$ & $24.9 \%$ \\
\hline 10 . & You can control the amount of pain you feel by changing your thoughts & $26.8 \%$ & $25.9 \%$ & $47.3 \%$ \\
\hline 11. & To know your pain, the best way is to go to the health care facility & $93.2 \%$ & $2.9 \%$ & $3.9 \%$ \\
\hline 12. & LBP gets progressively worse later in life & $71.7 \%$ & $10.7 \%$ & $17.6 \%$ \\
\hline
\end{tabular}

$\mathrm{A}^{*}=$ Agree, $\mathrm{DN}^{*}=$ Don't Know, $\mathrm{D}^{*}=$ Disagree, For the clarity of the table, the responses "strongly agree" and "agree" were collapsed into "agree" and the responses "strongly disagree" and "disagree" were collapsed into "disagree"

Calculating the responses in only three categories as in Table 3, the results show that the majority of participants believe that, people with LBP should avoid movements that involve the spine as they may cause more injury to the back (92.7\%), and that people with LBP should avoid physical activities and abstain from their regular duties for fear of causing more injury to their back $(68.3 \%)$. The results also showed that, $69.8 \%$ believed that their LBP will eventually stop them from working and that, they might not be able to do what they really want to do $(44.8 \%)$.Furthermore, $71.7 \%$ held a belief that their LBP will get progressively worse later in life.

Based on the Table 3, further analysis was carried out, intending to identify the proportion of the participants who had positive attitudes/beliefs and for those with negative attitudes and beliefs based on the twelve given statements. Statements, 2, 7, 10 and 11 were positively directed statements, thus the positive opinion included the response "agree" and "strongly agree", while "disagree" and "strongly disagree" responses indicate negative opinion on these statements. Statements 1, 3, 4, 5, 6, 8, 9 and 12 were negatively directed statements, therefore the positive 
opinion on these statements was represented by response "disagree" and "strongly disagree", while the negative opinions included the responses "agree" and "strongly agree". Statistical calculation demonstrated that the total number of participants who demonstrated positive attitudes and beliefs in all given 12 statements were only (33.2\%) and the majority $(66.8 \%)$ demonstrated negative attitudes and beliefs about their LBP (mean score 31.89; SD=4.87).

\section{Associations between Attitudes and Beliefs and the Selected Variables}

We attempted to identify any associations between the attitudes and beliefs of the participants with the variables such as age, gender, education level, marital status and residential area of the participants.

Although amongst the majority of the participants who portrayed negative attitudes and beliefs towards their LBP were female (69.7\%), Pearson Chi-square test did not reveal any association between the gender of the participants and their attitudes and beliefs $(p=0.35)$. Similarly, there was no any significant relationship between their age $(p=0.39)$ and the level of education of the participants $(\mathrm{p}=0.17)$ as shown in Table 4 .

Table 4. Summary of association between attitudes/beliefs and selected variables

\begin{tabular}{|c|c|c|c|}
\hline Characteristic & Positive attitudes and beliefs (\%) & Negative attitudes and beliefs (\%) & Chi-square statistic(p-value) \\
\hline \multicolumn{4}{|l|}{ Gender } \\
\hline Male & 36.5 & 63.5 & \multirow{2}{*}{$\chi 2=0.88\left(1^{*}\right)=, p=0.35$} \\
\hline Female & 30.3 & 69.7 & \\
\hline \multicolumn{4}{|l|}{ Age (years) } \\
\hline $15-24$ & 50 & 50 & \multirow{6}{*}{$\chi^{2}=5.23\left(5^{*}\right)=, p=0.39$} \\
\hline $25-34$ & 37 & 63 & \\
\hline $35-44$ & 36.4 & 63.6 & \\
\hline $45-54$ & 32.3 & 67.7 & \\
\hline $55-64$ & 20.9 & 79.1 & \\
\hline 65 and above & 42.9 & 57.1 & \\
\hline \multicolumn{4}{|l|}{ Level of education } \\
\hline Never went to school & 33.3 & 66.7 & \multirow{4}{*}{$\chi 2=5.09(3 *)=, p=0.17$} \\
\hline Primary level & 37.8 & 62.2 & \\
\hline Secondary level & 26.5 & 73.5 & \\
\hline Tertiary level & 0 & 100 & \\
\hline \multicolumn{4}{|l|}{ Marital status } \\
\hline Single & 45.8 & 54.2 & \multirow{6}{*}{$\chi 2=9.33\left(5^{*}\right)=, p=0.09$} \\
\hline Married & 34.6 & 65.4 & \\
\hline Divorced & 15.8 & 84.2 & \\
\hline Separated & 0 & 100 & \\
\hline Widow & 24 & 76 & \\
\hline Widower & 16.7 & 83.3 & \\
\hline \multicolumn{4}{|l|}{ Residential area } \\
\hline Urban & 36.1 & 63.9 & \multirow{2}{*}{$\chi 2=2.62(1 *)=, p=0.11$} \\
\hline Rural & 23.4 & 76.6 & \\
\hline
\end{tabular}

$\mathrm{p}=\mathrm{p}$-value, at $5 \%$ level of significance, $*$ degrees of freedom,

\section{Discussion}

Based on the results of this study, it shows that the majority of patients attending hospital physiotherapy outpatient departments in Malawi for LBP are females between the ages of 45 to 54 years, married, live in an urban area, and only have a primary level of education. The findings of this study are in conformity with several population based studies on LBP, conducted both in western and African countries which revealed that, women are more affected by LBP than men $[16,17,18,19]$. The female dominance over male gender in LBP could be due to the fact that, female have low pain threshold and are likely to report pain and seek health care than men [20, 21, 22]. The results further show that majority of the participants in this study had low level of education (primary level). These findings concur with the findings of Djavid et al and Tavafian et al, in their studies they both noted that the majority (more than $80 \%$ ) of the participants had a low level of education and lived on low income [23, 24].Moreover, low level of education has been associated with greater chances for an individual to develop LBP [25, 25, 27, 28].

Identifying patients' attitudes and beliefs regarding their LBP is of paramount importance, because it facilitates the management of their pain and enhances recovery [11]. Negative attitudes and beliefs on pain have been confirmed to be a barrier to achieving the desired treatment outcomes [12]. Our study strived to establish the attitudes and beliefs among LBP patients attending physiotherapy treatment in Malawi. The results show that out of the 205 participants, more than half $(67 \%)$ portrayed negative attitudes and beliefs regarding their LBP. These findings are consistent to many other previous studies [29, 30].

Although female participants portrayed more negative attitudes and beliefs regarding their pain, generally, there was no any significant association between gender and their 
beliefs. Consequently, majority of the participants (48\%) had primary level of education, married (51\%) and live in urban areas $(77 \%)$,but there was no statistical significance found between their level of education $(p=0.17)$, marital status $(p=0.09)$ and the area of residence $(p=0.11)$ and their attitudes and beliefs.

The consequences of the patients holding negative attitudes and beliefs regarding their LBP have been widely reported [13, 31, 33]. In this study for instance, (nearly 93\%) of the participants believed that, because of their LBP, any movement or physical activity, that will involve their back should be avoided as this may cause more harm to their already existing LBP. These findings are congruent with the findings of Keen et al [32] which found that, the majority of the participants with LBP in their study tended to avoid movements and physical activity; although some believed that keeping active could be the best way to easy their LBP. This is clear indications that, majority of patients with LBP tend to develop fear, leading to avoidance behavior [29], which increases the risk of developing chronic LBP and may be a significant indicator for development of disability and abstinence of physical activities [33].Moreover, persistent pain has been associated strongly with higher levels of chronicity and disability, psychosocial distress and enormous cost to the society [34].

On a similar note, Linton et al [13] indicate that, fearavoidance among LBP patients is usually linked with the beliefs that activity or movement is harmful and may aggravate the degree of pain. But the impact occurring as result of these negative attitudes and beliefs is quite substantial such that, the functional limitations imposed to an individual are more debilitating than the pain itself [38]. Therefore, educating patients on the possible negative impact of inactivity and positive influences of exercise may improve the likelihood of participating in a regular exercise program [39].

Of important to note however, is that, patients with LBP, anticipate to be disabled at one point in the course of their life due LBP. Nearly $70 \%$, of the participants in this study believed that, they will not recovery from their LBP because their pain would progressively get worse later in life. This is consistent with the findings of May [14] and Urquhart et al [30], they noted that patients with LBP believe that their pain is irrecoverable and they will not be able to do the activities, which were able to do prior to their pain. Holing such negative beliefs among patients with LBP is retrogressive and problematic, as it escalates pain chronicity, hindering achievement of treatment goal, leading to disability $[35,36]$.

\section{Implication of the Study}

This study has identified the negative attitudes and beliefs about LBP among patients attending treatment at physiotherapy outpatient departments in Malawi. It is probably the first study in Malawi which explored attitudes and beliefs among LBP patients attending physiotherapy in Malawi. The results highlighted the need for the health care providers who are involved in the management of patients with LBP, to identify patients' attitudes and beliefs regarding their pain, and to include patient health education in the management program. Patient health education changes patients' wrongful perceptions about their LBP, leading to the achievement of clinical outcomes and increased patient's satisfaction [40].

\section{Conclusion}

We concluded that, majority of patients with LBP in Malawi hold negative attitudes and beliefs about their LBP. Therefore, identification of patients' attitudes and beliefs regarding their pain, followed by provision of health education to patients about their LBP is necessary in the management of LBP. Health education may possibly change their negative attitudes and beliefs, contributing towards combating the development of chronic pain situations. This study did not differentiate between the attitudes and beliefs of acute versus chronic recurrent LBP patients. This may be a limitation of this study. It would therefore, be of importance if this will be addressed in further studies because patients with acute LBP and those with chronic recurrent LBP may not hold similar beliefs regarding their LBP.

\section{References}

[1] Vanti C, Gasperini M,Morsillo F, Pillastrini, P (2010). Low back pain in adolescents gymnasts. Prevalence and risk factors. Scienza Rehabilitation, 12(2), 45-50.

[2] Norris, CM (2000). Back stability: United States of America: Edward brothers

[3] Van Vuuren, BJ, Becker, PJ, Van Heerden, HJ, Zinzen, E, Meunisen, R. (2005). Low back pain problems and occupational risk factors in a South African steel industry. American Journal of Industrial Medicine, 47(5), 451-457.

[4] Louw, QA, Morris, LD, Grimmer, KS (2007). The Prevalence of low back pain in Africa: A systematic review. BMC Musculoskeletal Disorders, 8:105 doi: 10.1186/14712474-8-105

[5] Volinn, E (1997). The Epidemiology of low back pain in the rest of the world. A review survey in low and middle income countries. Spine, 22, 1747-1757.

[6] Cole, MH, \& Grimshaw, PN (2003). Low back pain and lifting: A review of epidemiology and aetiology. Journal of Prevention, Assessment and Rehabilitation, 21, 173-184.

[7] Adam, SR (2009). Back pain and sciatica. Anaesthesia Analogy, 85, 1066-1070.

[8] Ng'uurah, JN, Frantz, JM. (2006). Health education needs among individuals with low back pain. South African Journal of Physiotherapy, 62(4), 22-27. 
[9] Allock, N, Elkan, R, Williams, J (2007). Patients referred to pain management clinic: Beliefs, expectations and priorities. Journal of Advanced Nursing, 60(3), 248-256.

[10] Henrotin, YE, Cedrasch, C, Duplan, B, Bazil, T, Duquesnoy, B (2006). Information and low back pain management: A systematic review. Spine, 31(11), E326- E334.

[11] Linton, SJ, Helsing, AL,Halden, KA (1998). Population based study of spinal pain among 35-45 year old individuals: Prevalence, sick leave and health care use. Spine, 23, 14571463.

[12] Symonds, TL, Burton, AK, Tillotson, KM, Main, CJ (1996). Do attitudes and beliefs influence work loss due to low back trouble? Occupational Medicine, 46, 25-32.

[13] Linton, SJ, Vlaeyen, J, Ostelo, R (2002). The back pain beliefs of health care providers: Are we fear-avoidant? Journal of Occupational Rehabilitation, 12, 223-232.

[14] May, S (2007). Patients' attitudes and beliefs about back pain and its management after physiotherapy for low back pain. Physiotherapy Research International, 12(3), 123-135.

[15] Polit, DF, Beck, CT, Hungler, BP (2001). Essentials of Nursing Research, Methods, Appraisal, and Utilization (5thed.). Philadelphia: Lippincott Publishers

[16] Sikiru, L, \&Hanifa, S (2010). Prevalence and risk factors of low back pain among nurses in a typical Nigerian hospital. African Health Sciences, 10, 26-30.

[17] Vindigni, D, Bruce, F, Walker, Jamison, JR, Costa, CD, Parkinson, L, Blunden, S (2005). Low back pain risk factors in a large rural Australian Aboriginal community. An opportunity for managing co-morbidities? Chiropractic and Osteopathy, 13:21 doi: 10.1186/1746-1340-13-21

[18] Omokhodion, FO, Umar, US, Ogunnowo, BE (2000). Prevalence of low back pain among staff in rural hospital in Nigeria. Occupation Medicine, 50(2), 107-110.

[19] Macarthur, AJ, Macarthur, C, Weeks, SK (1997). Is epidural anaesthesia in labor associated with chronic low back pain? A Prospective cohort study. Anaesthesia Analogy, 85(5), 1066-1070.

[20] Chiu, TWT, Lam, KWP (2007). The prevalence of and risk factors for neck pain and upper limb pain among secondary school teachers in Hong Kong. Journal of Occupational Rehabilitation, 17, 19-32.

[21] Bruce, F, Walker, DC, Reinhold, M, William, DG (2004). Low back pain in Australian adults' health provider utilization and care seeking. Journal of Manipulative and Physiological Therapeutics, 27(5), 327-335.

[22] Jin, K, Sorock, GS, Courtney, TK (2004). Prevalence of low back pain in three occupational groups in Shanghai, People's Republic of China. Journal of Safety Research, 35, 23-28.

[23] Djavid, GE, Mehrdad, R, Ghasemi, M, Zadeh, HH, Manesh, AS, Pouryaghoub, G (2007). In chronic low back pain, low level laser therapy combined with exercise is more beneficial than exercise alone in the long term: A randomized trial. Australian Journal of Physiotherapy, 53, $155-160$.

[24] Tavafian, SS, Eftekhar, H, Mohammad K, Jamshidi, AR, Assasi, N, Shojaeezadeh, D, Ghofranipour, F (2004).
Patient's knowledge, perception and belief about the reasons of low back pain. Iranian Journal of Public Health, 33(4), $57-60$.

[25] Hagen, K, Zwart, JA, Svebak, S, Bovim, G, Jacob, SL (2005). Low socioeconomic status is associated with chronic musculoskeletal complains among 46,901 adults in Norway. Scandinavian Journal of Public Health, 33(4), 268-375.

[26] Ihlebaeck, C, Ericksen, HR (2005). Myths and perceptions of back pain in the Norwegian population, before and after the introduction of guidelines for acute back pain. Scandinavian Journal of Public Health, 33, 401-406.

[27] Goldberg, MS, Scott, SC, Mayo, NE (2000). A review of the association between cigarette smoking and the development of nonspecific back pain and related outcomes. Spine, 25, 995-1014.

[28] Lake, JK, Power, C, Cole, TJ (2000). Back pain and obesity in the 1958 British birth cohort: Cause or effect? Journal of Clinical Epidemiology, 53, 245-250.

[29] Rainvile, J, Smeet, RJ, Bendix, T, Tveito, TH, Poiravadeaus, S, Indahl, AJ (2011). Fear avoidance beliefs and pain avoidance in low back pain- translating research in to clinical practice. Spine Journal 11: 895-903.

[30] Urquhart, DM., Bell, RJ, Cicuttini, FM, Cui, J, Forbes, A, Davis, SR (2008). Negative beliefs about low back pain are associated with high pain intensity and high level disability in the community-based women. BMC Musculoskeletal Disorders, 9:148 doi: 10.1186/1471-2474-9-148

[31] Picavet, HSJ, Vlaeyen, JWS, Schouten, JSA (2002). Pain catastrophizing and kinesiophobia: Predictors of chronic low back pain. American Journal of Epidemiology, 156, 10281034

[32] Keen, S, Dowell, DC, Hurst, K, Klaber-Moffett, JA, Tovey, P, Williams, R (1999). Individual with low back pain: How do they view physical activity? Family Practice, 16, 39-45.

[33] Fritz, JM, George, SZ, Delitto, A (2001). The role of fearavoidance beliefs in acute low back pain: Relationships with current and future disability and work status. Pain, 94, 7-15

[34] Waddell, G. (Ed.) (2004). Pain and disability. The back pain revolution (2nd ed.). Edinburg. UK: Churchill Livingstone.

[35] Linton, SJ, Buer, N, Vlaeyen, J W S,Hellsing, AL (1999). Are fear-avoidance beliefs related to the inception of an episode of back pain? A prospective study. Psychol. Health 14: 1051-1059

[36] Linton, SJ, Nordin, E (2006). A 5-year follow-up evaluation of the health and economic consequences of an early cognitive behavioral intervention for back pain: a randomized, controlled trial. Spine31: 853-858.

[37] Jensen, JN,Albertsen, K, Borg, V, Nielsen, KN (2009). The predictive effect of fear-avoidance beliefs on low back pain among newly qualified health care workers with and without previous low back pain: a prospective cohort study. BMC Musculoskeletal Disorders 2009,10:117 doi:10.1186/14712474-10-117

[38] Leeuw, M, Goossens, ME Linton, SJ, Crombez, G, Boersma, K, Vlaeyen, JW (2006). The Fear-Avoidance Model of Musculoskeletal Pain: Current State of Scientific Evidence. Journal of Behavioral Medicine, 30 (1): 77- 94 
118 Tarimo Nesto and Ina Diener: Patients with Low Back Pain in Malawi: Their Attitudes and Beliefs on Their Low Back Pain

[39] Hanney, WJ, Kolber, MJ, Beekhuizein, KS (2008). Implications for physical activity in the population with low back pain. American Journal of Lifestyle Medicine, 3(1), 63-70.
[40] Sarah, K (2000). Back sufferer's bible. You can treat your own back. Australia: Allenand and Unwin publishers. 